\title{
Treatment with ActRIIB-mFc Produces Myofiber Growth and Improves Lifespan in the Acta1 H40Y Murine Model of Nemaline Myopathy
}

Jennifer Tinklenberg, ${ }^{* \dagger}$ Hui Meng, ${ }^{*}$ Lin Yang,${ }^{\ddagger}$ Fujun Liu, ${ }^{\ddagger}$ Raymond G. Hoffmann, ${ }^{\S}$ Mahua Dasgupta, ${ }^{\S}$ Kenneth P. Allen, Alan H. Beggs, " Edna C. Hardeman, ${ }^{* *}$ R. Scott Pearsall, ${ }^{\dagger \dagger}$ Robert H. Fitts, ${ }^{\ddagger \dagger}$ and Michael W. Lawlor ${ }^{* \dagger}$

\begin{abstract}
From the Division of Pediatric Pathology, ${ }^{*}$ Department of Pathology and Laboratory Medicine, the Neuroscience Research Center, ${ }^{\dagger}$ the Quantitative Health Sciences Section, ${ }^{\S}$ Department of Pediatrics, and the Biomedical Resource Center, ${ }^{\Uparrow}$ Office of Research, Department of Microbiology and Molecular Genetics, Medical College of Wisconsin, Milwaukee, Wisconsin; the Department of Biomedical Engineering, ${ }^{\ddagger}$ University of Florida, Gainesville, Florida; the Division of Genetics and Genomics," The Manton Center for Orphan Disease Research, Boston Children's Hospital, Harvard Medical School, Boston, Massachusetts; the Neuromuscular and Regenerative Medicine Unity, ** Department of Anatomy, University of New South Wales, Sydney, Australia; Acceleron Pharma Inc., ${ }^{\dagger \dagger}$ Boston, Massachusetts; and the Department of Biological Sciences, ${ }^{\ddagger \ddagger}$ Marquette University, Milwaukee, Wisconsin
\end{abstract}

Accepted for publication

February 11, 2016.

Address correspondence to Michael W. Lawlor, M.D., Ph.D., 9000 W Wisconsin Ave., TBRC Bldg., Room C4490, Milwaukee, WI 53226. E-mail: mlawlor@mcw.edu.

\begin{abstract}
Nemaline myopathies (NMs) are a group of congenital muscle diseases caused by mutations in at least 10 genes and associated with a range of clinical symptoms. NM is defined on muscle biopsy by the presence of cytoplasmic rod-like structures (nemaline rods) composed of cytoskeletal material. Myofiber smallness is also found in many cases of NM and may represent a cause of weakness that can be counteracted by treatment. We have used i.p. injection of activin type IIB receptor (ActRIIB)-mFc (an inhibitor of myostatin signaling) to promote hypertrophy and increase strength in our prior murine work; we therefore tested whether ActRIIB-mFc could improve weakness in NM mice through myofiber hypertrophy. We report a study of ActRIIB-mFc treatment in the Acta1 H40Y mouse model of NM. Treatment of Acta1 H40Y mice produced significant increases in body mass, muscle mass, quadriceps myofiber size, and survival, but other measurements of strength (forelimb grip strength, ex vivo measurements of contractile function) did not improve. Our studies also identified that the complications of urethral obstruction are associated with mortality in male hemizygote Acta1 H4OY mice. The incidence of urethral obstruction and histologic evidence of chronic obstruction (inflammation) were significantly lower in Acta1 $\mathrm{H} 40 \mathrm{Y}$ mice that had been treated with ActRIIB-mFc. ActRIIB-mFc treatment produces a mild benefit to the disease phenotype in Acta1 H40Y mice. (Am J Pathol 2016, 186: 1568-1581; http://dx.doi.org/10.1016/j.ajpath.2016.02.008)
\end{abstract}

The nemaline myopathies (NMs) are a clinically and genetically heterogeneous group of diseases, with a wide range of clinical phenotypes ${ }^{1}$ associated with mutations in at least 10 genes (ACTA1, NEB, TPM3, TPM2, TNNT1, CFL2, KBTBD13, KLHLAO, KLHL41, and LMOD3). ${ }^{2-5}$ With the exception of $K B T B D 13$, the proteins encoded by all these genes are structural components of (or are associated with) the sarcomeric thin filament, which is an essential component of muscle contraction. ${ }^{6,7}$ The unifying feature of all NM cases is the presence of characteristic nemaline rods

\footnotetext{
Supported by NIH grants K08 AR059750 (M.W.L.), R01 HD075802 (A.H.B.), and R01 AR044435 (A.H.B.), the Clinical and Translational Science Institute of Southeastern Wisconsin (through National Center for Advancing Translational Sciences grant 8UL1 TR000055; M.W.L.), the AUism Charitable Foundation (A.H.B.), and A Foundation Building Strength (M.W.L. and A.H.B.). The Neuroscience Research Center's Behavioral Core Facility at the Medical College of Wisconsin was funded by the Research and Education Initiative Fund, a component of the Advancing a Healthier Wisconsin Endowment at the Medical College of Wisconsin.
}

Disclosures: M.W.L. is a member of the advisory boards of and has been supported by sponsored research agreements from Audentes Therapeutics. M.W.L. is also a paid consultant for Sarepta Therapeutics and a scientific collaborator with Acceleron Pharma and Pfizer. A.H.B. is a member of the scientific advisory board of Audentes Therapeutics. R.S.P. is a full-time employee and shareholder of Acceleron Pharma. This article describes experiments on mice using a therapeutic agent (ActRIIB-mFc) that is not currently approved by the US Food and Drug Administration. 
on skeletal muscle biopsy, which are aggregates of $\alpha$-actinin and other sarcomeric proteins. ${ }^{8}$ Although nemaline rods are a critical diagnostic feature of NM, their abundance, size, and distribution do not correlate well with disease severity, ${ }^{2}$ and their direct contribution to the weakness seen in NM is questionable. Another nonspecific pathologic feature that is seen in many cases of NM is myofiber smallness (or hypotrophy ${ }^{9}$ ), which most often involves the type 1 myofiber population. This pattern of myofiber hypotrophy is similar to that seen in other congenital myopathies, particularly congenital fiber-type disproportion, which has genetic and phenotypic overlap with some subsets of NM. ${ }^{10,11}$ Myofiber hypotrophy represents a potentially reversible pathologic phenotype that has a known association with muscle strength and should thus be considered as a therapeutic target for all cases of NM. Currently, there is no effective treatment for NM.

Because myofiber smallness or suboptimal numbers of sarcomeres may contribute to weakness in NM, we hypothesized that induction of myofiber hypertrophy would be of symptomatic benefit in murine models of NM. Myostatin binds to (and signals through) the activin type IIB receptor (ActRIIB) to activate the transforming growth factor- $\beta$ pathway, which prevents progression through the cell cycle and down-regulates several key processes related to myofiber hypertrophy. ${ }^{12,13}$ Nonfunctional decoys of ActRIIB can be used to inhibit this negative regulator of myofiber size, leading to myofiber hypertrophy. In our prior work, we used ActRIIB-mFc, a soluble activin type IIB receptor, to produce myofiber hypertrophy in wild-type (WT) mice and in two murine models of X-linked myotubular myopathy (XLMTM). ${ }^{14,15}$ In both these studies, the functional effect of hypertrophy on XLMTM muscle was significantly limited by the abnormalities of excitation-contraction coupling (ECC) that are also encountered in this disease. Because physiologic studies performed in NM mouse models ${ }^{16-20}$ and myofibers from human patients with $\mathrm{NM}^{21-23}$ do not indicate problems with ECC in NM, we hypothesized that myostatin/ActRIIB inhibition would produce both hypertrophy and significant functional benefits in murine models of NM.

Although a variety of murine models are available for testing, the Actal H40Y mouse represented a good first model for the evaluation of myostatin inhibition due to its behavioral phenotype and use in prior treatment studies. ${ }^{18}$ Actal H40Y mice develop moderate weakness, pathologic features similar to those of NM, and mortality of approximately half of hemizygote males at 1 to 3 months of age. ${ }^{18}$ The pathologic phenotype and clinical course of Actal H40Y mice was improved by crossing them with transgenic mice that produced myofiber hypertrophy through the overexpression of insulin-like growth factor-1 or FHL1 (but not c-ski), ${ }^{18}$ suggesting a benefit from at least some forms of hypertrophy in these mice. In this study, Actal H40Y mice and WT littermates were injected twice per week with 10 $\mathrm{mg} / \mathrm{kg}$ of ActRIIB-mFc, starting at 2 weeks of age and lasting until death or 16 weeks of age. Treatment of Actal H40Y mice produced myofiber hypertrophy and improved survival without measurable increases in limb strength. We also identified an unexpected cause of death in Actal H40Y mice (urinary outlet obstruction) that may represent a broader-reaching cause of mortality in muscle disease models. Our studies have found an important new phenotype of weakness that may affect survival in murine models of neuromuscular disease, while also revealing that ActRIIB inhibition has the potential to improve pathologic features and disease course in NM.

\section{Materials and Methods}

\section{Live Animal Studies}

All studies were performed with approval from the Institutional Animal Care and Use Committee at The Medical College of Wisconsin and Marquette University. Genotyping of the Actal $\mathrm{H} 40 \mathrm{Y}$ mice was performed as previously described. ${ }^{18}$ Male WT and Actal H40Y mice were given i.p. injections twice per week with ActRIIB-mFC (also termed RAP-031; Acceleron Pharma, Cambridge, MA) at a dose of $10 \mathrm{mg} / \mathrm{kg}$ or an equivalent volume of Tris-buffered saline (the vehicle used with ActRIIB-mFc) as previously described $^{14}$ from 14 days until 4 months of life. Animals were euthanized at 4 months of life because of a plateau in observable therapeutic effects. Animals were weighed daily during the treatment period beginning at 2 weeks of age when the first injection was given. Once the animals were weaned at the age of 3 weeks, forelimb grip strength was measured biweekly using a grip strength meter (Columbus Instruments, Columbus, $\mathrm{OH}$ ) by placing the animal on a horizontal grid and allowing it to pull away from the experimenter using only its forelimbs. The maximum of three independent measurements, with a 1-minute recovery period between measurements, was used for subsequent statistical analysis. To evaluate antigravity hanging performance, animals were tested biweekly by placing the animal on a rigid mesh surface, inverting the surface at a height of approximately $40 \mathrm{~cm}$ above a cage that contained at least 3 $\mathrm{cm}$ of bedding material, and recording the amount of time necessary for the animal to fall back into the cage. Animals that did not fall within 60 seconds were lowered back into their cages. The maximum of three independent measurements, with a 1-minute recovery period between measurements, was used for subsequent statistical analysis. Beginning at 1 month of age, mice were placed in a circular chamber $(49.5 \mathrm{~cm})$ and allowed to freely explore the enclosure for 10 minutes once a month. The open field tests were videotaped and analyzed for the total distance traveled by ANY-maze software version 3.96 (Stoelting, Wood Dale, IL). Also beginning at 1 month of age, animals were placed on a treadmill moving at 4 to $6 \mathrm{~m} / \mathrm{min}$ (Columbus Instruments) every other week and monitored for the number of falls onto shock bars that occurred during 10 minutes. 


\section{Pathologic Evaluation and Tissue Collection}

Animals were euthanized with carbon dioxide followed by cervical dislocation. Animals were photographed after the removal of the skin from the torso and limbs. The quadriceps, gastrocnemius, triceps, soleus, extensor digitorum longus (EDL), and diaphragm muscles were removed, weighed, and frozen in liquid nitrogen-cooled isopentane.

\section{In Vitro Contractile Properties/Fatigability}

\section{Muscle Preparation}

Mice were euthanized with carbon dioxide and the EDL and soleus muscles rapidly removed and placed into a dissecting chamber containing a room temperature $\left(23^{\circ} \mathrm{C}\right)$ Ringer solution $(124 \mathrm{nM} \mathrm{NaCl}, 4 \mathrm{nM} \mathrm{KCl}, 1 \mathrm{nM} \mathrm{MgCl} 2,1 \mathrm{nM}$ $\mathrm{KH}_{2} \mathrm{PO}_{4}, 25 \mathrm{nM} \mathrm{NaHCO}_{3}$, and $2 \mathrm{nM} \mathrm{CaCl}_{2}$ gassed with $95 \%$ $\mathrm{O}_{2}$ to $5 \% \mathrm{CO}_{2}, \mathrm{pH}$ 7.40). Muscles were prepared for study by tying a small loop onto the distal and proximal tendon at the fiber tendon junction with 4-0 silk thread. ${ }^{24}$ To determine the contractile properties and fatigability of the EDL and soleus, each muscle was transferred to an experimental chamber containing Ringer solution $\left(95 \% \mathrm{O}_{2}\right.$ to $\left.5 \% \mathrm{CO}_{2}\right)$ and suspended with the 4-0 loops between a Cambridge model 352 ergometer (Aurora Scientific, Aurora, ON) and a fixed post.

\section{Isometric Force Measurement}

Each preparation was adjusted to its optimal length at which maximal twitch and tetanic tension was elicited (resting tension $=2 \mathrm{~g}$ ) and isometric contractile properties studied as described previously and briefly reviewed here. ${ }^{25}$ The muscles were stimulated along their entire length with platinum wire electrodes. Peak twitch tension was elicited with $0.5-\mathrm{ms}$ supermaximal pulse, and contraction time was measured as the time from the onset of force development to peak force. Half relaxation time $(1 / 2 \mathrm{RT})$ was the time required for force to decay to half of the maximum twitch value. Peak tetanic tension $\left(\mathrm{P}_{\mathrm{o}}\right)$ was elicited by stimulation at $100 \mathrm{~Hz}$ for $500 \mathrm{~ms}$ for the soleus and $150 \mathrm{~Hz}$ for $200 \mathrm{~ms}$ for the EDL. For the twitch and tetanus, the maximum rate of force development and decay were determined by measuring the peak slope of the contraction and relaxation, respectively. The output from the transducer was amplified and sampled at $3.3 \mathrm{kHz}$ by a Pentium computer using custom-made software.

\section{Force-Velocity and Power Curves}

The force-velocity association was determined, as described previously. ${ }^{25}$ At the plateau of peak tetanic contraction, the computer switched the ergometer from length to force control, and the load on the muscle was rapidly stepped to maintain three loads less than peak force. Force was held at each load for $100 \mathrm{~ms}$ for the soleus and $40 \mathrm{~ms}$ for the EDL, during which time the change in muscle length was monitored. The computer calculated the velocity of shortening from the slope of the length change during the last half of each load step. This procedure was repeated four times, such that 12 different loads were studied for each muscle. Loads were expressed as a percentage of peak force. $V_{\max }$ was calculated by the straightline form of the Hill equation $\left(\mathrm{P}_{0}-\mathrm{P}\right) / V=\mathrm{P} / b+a / b$ by using loads $\leq 50 \%$ of $\mathrm{P}_{0}$, where $\mathrm{P}$ is force, $V$ is velocity, and $a$ and $b$ are constants with the dimensions of force and velocity, respectively. A hyperbolic curve was fit to the data by using the Hill equation $(\mathrm{P}+a)(V+b)=\left(\mathrm{P}_{0}+a\right) b$.

Muscle power was calculated from the fitted forcevelocity parameters and the maximum isometric force that was developed during the experiment. ${ }^{25}$ Absolute power was defined as the product of force (in $\mathrm{mN}$ ) and shortening velocity $(\mathrm{ML} / \mathrm{s})$, yielding a final value of $\mathrm{mN} \cdot \mathrm{ML}^{-1} \cdot \mathrm{s}^{-1}$.

\section{Muscle Histologic Findings}

Cross sections $(8 \mu \mathrm{m})$ of isopentane-frozen quadriceps muscles were taken midway down the length of the muscle and stained with hematoxylin and eosin or Gomori trichrome for evaluation using an Olympus BX53 microscope with an Olympus DP72 camera and cellSens standard software (Olympus, Center Valley, PA). Fiber size was determined through measurements of MinFeret diameter ${ }^{14}$ because this measurement offers a myofiber size measurement that is relatively independent of fiber orientation. ${ }^{26}$ To evaluate fiber size and fiber type-specific responses, $8-\mu \mathrm{m}$ frozen transverse sections of quadriceps muscle were doublestained with rabbit anti-dystrophin antibodies (ab15277; 1:100; Abcam, Cambridge, MA) and mouse monoclonal antibodies against myosin heavy chain type $2 \mathrm{~b}$ (clone BF-F3; 1:50; Developmental Studies Hybridoma Bank, Iowa City, IA). Secondary antibodies included Alexa Fluor 488conjugated anti-mouse IgM (1:400; Sigma-Aldrich, St. Louis, MO) and Alexa Fluor 488-conjugated anti-rabbit IgG (1:200; Molecular Probes, Carlsbad, CA). Because of variation in the number and type of oxidative fibers (type 1 and $2 \mathrm{a}$ fibers) in mouse muscle, quantitation was performed by evaluating the type $2 \mathrm{~b}$ myosin positive (glycolytic) and type $2 \mathrm{~b}$ myosin negative (oxidative) populations on a whole slide scan of one quadriceps muscle from six vehicle-treated WT mice, six ActRIIB-mFc-treated WT mice, six vehicle-treated Actal $\mathrm{H} 40 \mathrm{Y}$ mice, and six ActRIIB-mFc-treated Actal H40Y mice. MinFeret diameter was evaluated using a novel automated technique developed by Dr. Lin Yang, as we have previously reported. ${ }^{14,15}$ Glutaraldehyde-fixed strips of quadriceps muscle were collected from some mice, and electron microscopy was performed at the Medical College of Wisconsin's Electron Microscopy Core Facility.

\section{Organ Histologic Findings}

Organs were removed and fixed in $10 \%$ neutral buffered formalin for subsequent paraffin embedding at the Children's Hospital of Wisconsin Research Institute Histology Core, as previously described. ${ }^{27,28}$ The histopathologic 
findings of all thoracic and abdominal organs were assessed in a pilot group of four to six animals per treatment group using hematoxylin and eosin-stained slides. After recognizing the distribution of genitourinary disease in Actal H40Y males, the pelvic contents of subsequent cohorts of mice were dissected and histologically evaluated in the sagittal and axial planes. Because the axial view of the membranous urethra offered the most consistent view of skeletal muscle features between animals, blocks revealing axial sections of the membranous urethra at a comparable site (including the urethra, prostate, striated muscle, and rectum) were further evaluated by staining for dystrophin (ab15277; Abcam) or skeletal muscle actin (ab52218; Abcam) to determine the degree of NM-associated disease in urethral striated muscles and visualized using biotinylated horse anti-rabbit IgG (BA-1100; Vector Laboratories, Burlingame, CA). These findings were quantified by manually counting the number of fibers with actin-positive aggregates and the total number of fibers in a single medium-powered (magnification, $\times 100$ ) field from each of the two urethral striated muscle fascicles that were reproducibly found along the lateral aspects of the urethra in axial sections. The skeletal muscle actin antibody that was used had cross-reactivity with cardiac actin and smooth muscle actin on testing of this antibody in cardiac and aortic tissue, respectively.

\section{Hypertrophic Pathway Studies}

Muscle tissues from the quadriceps muscle was frozen at the time of necropsy and stored at $-80^{\circ} \mathrm{C}$ until analysis. Frozen muscles were crushed in liquid nitrogen and homogenized with lysing buffer (Cell Signaling Technology, Danvers, MA) containing protease inhibitor (Roche, Basel, Switzerland) and phosphatase inhibitor (Roche). Western blot procedures were performed as previously described. ${ }^{15,29}$ Transferred proteins were probed with antibodies against a variety of antigens. Antibodies recognizing the following antigens were all obtained from Cell Signaling Technologies (Danvers, MA): Akt (4691), phospho-Akt (Ser473; 4060), phospho-Akt (Thr308; 2965), p70-S6K (2708), phospho-p70S6K (Thr421/Ser424; 9204), S6 Ribosomal Protein (2217), phospho-S6 Ribosomal Protein (Ser240/244; 5364), phosphoeEF2k (Ser366; 3691), and phospho-4E-BP1 (Thr37/46; 2855). Other antibodies used for Western blot studies recognize: myostatin (MAB788; R\&D Systems, Minneapolis, MN), ActRIIB (ab76940; Abcam), and glyceraldehyde-3phosphate dehydrogenase (G8795; Sigma-Aldrich) and were visualized using chemiluminescent horseradish peroxidase antibody detection reagent (Denville Scientific, Metuchen, NJ). Adequacy of transfer was determined by Ponceau $S$ staining. Quantification of protein levels normalized to glyceraldehyde-3-phosphate dehydrogenase was performed with ImageJ software version $1.48(\mathrm{NIH}$, Bethesda, MD; http://imagej.nih.gov/ij). ${ }^{30}$ Samples from four animals per treatment group were used for analysis.

\section{Statistical Analysis}

Statistical evaluation was performed using Prism software version 6.0 (GraphPad Software, Inc., La Jolla, CA) by SAS software version 9.2 (SAS Institute Inc., Cary, NC) or STATA software version 13.1 (StataCorp, Chicago, IL). For statistical analysis of animal weight, forelimb grip strength, open field antigravity hanging performance, and treadmill performance, analyses of variance were performed with Bonferroni posttests. For muscle weight and mean myofiber diameter measurements, generalized linear models with Bonferroni posttests were performed. The survival analysis used Kaplan-Meier with a log-rank test. The in vitro contractile property data were analyzed with multiple unpaired $t$-tests using Holm-Sidak method and $\alpha=5 \%$. For statistical analysis of Western blot data, $t$-tests were used to compare protein expression among different genotypes or treatments.

\section{Results}

We assessed the effects of ActRIIB-mFc treatment in male heterozygote Actal $\mathrm{H} 40 \mathrm{Y}$ mice starting at 14 days of life. Male mice were used because they reportedly experienced mortality (52\% to $61 \%$ ) as a component of the disease phenotype, whereas mortality was only reported rarely in female mice (3\% to 5\%). ${ }^{18}$ Mice were dosed twice per week, consistent with our prior studies using ActRIIB-mFc, and treatment efficacy was assessed using a variety of behavioral, physiologic, and pathologic measurements. Study time points included terminal stage of disease [in animals who reached this stage before 16 weeks of life (WOL)] or at $16 \mathrm{WOL}$.

\section{Weight Studies}

In animals that received vehicle injections, Actal H40Y mice were distinguishable from WT mice on the basis of weight beginning at $5 \mathrm{WOL}(P<0.05)$ (Figure $1 \mathrm{~A})$. These differences increased and persisted during the period analyzed (up to 16 weeks of age) $(P<0.0001)$. ActRIIB$\mathrm{mFc}$-treated WT mice had significant weight gains compared with vehicle-treated WT mice starting at 5 WOL $(P<0.05)$, and this difference increased and persisted up to 16 weeks of age $(P<0.0001)$. ActRIIB-mFc treatment of Actal H40Y mice resulted in significant animal weight differences compared with vehicle-treated mutant mice starting at 6 WOL $(P<0.05)$, but the relative effect diminished over time as weight differences between these groups became nonsignificant at $9.5 \mathrm{WOL}$ and persisted as a nonsignificant trend until the end of the study at 16 WOL.

\section{Behavioral Studies}

Muscle weakness was assessed by evaluating forelimb grip strength, antigravity hanging performance, open field activity, and treadmill performance. Interestingly, assays for 

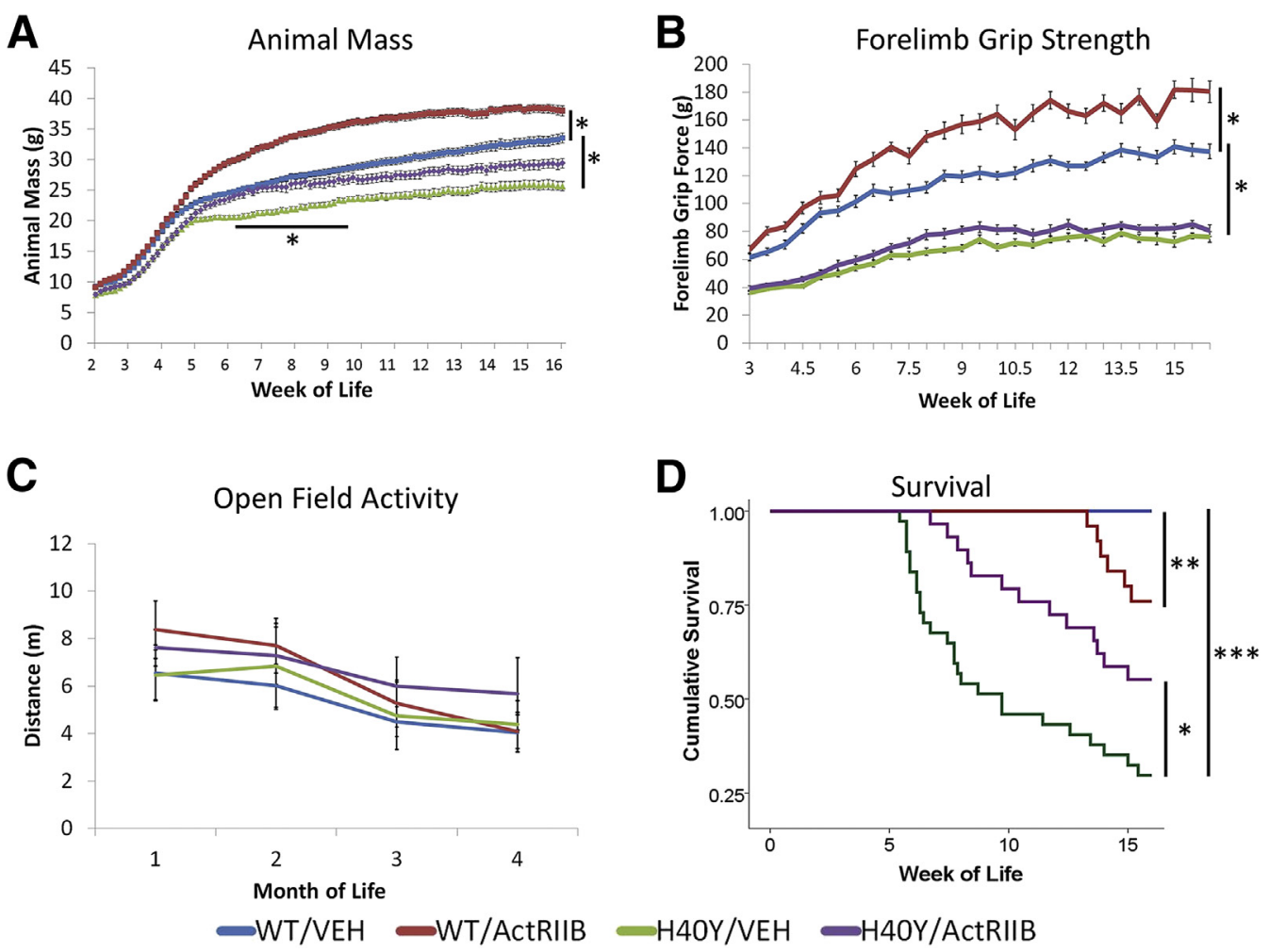

Figure 1 Phenotypic findings in VEH- and ActRIIB-mFc-treated mice. A: Total body weight of VEH- and ActRIIB-mFc - treated mice. B: Forelimb grip force of VEH- and ActRIIB-mFc-treated mice. C: Open field activity (expressed in meters traveled in 10 minutes) of VEH- and ActRIIB-mFc-treated mice. D: Kaplan-Meier survival curves for VEH- and ActRIIB-mFc-treated mice. Bars and asterisks denote significant differences between treatment groups with relevant comparisons. Note that the bar and asterisk in A illustrate a significant difference between the H40Y/VEH and H40Y/ActRIIB groups only between 6.5 and 9 weeks of age. The survival comparison in D between WT/ActRIIB and H40Y/ActRIIB did not reach statistical significance $(P=0.062)$. Data are expressed as means \pm SEM (A-C). $n=25$ for the WT/VEH group, 19 for the WT/ActRIIB group, 32 for the H4OY/VEH group, and 24 for the H40Y/ActRIIB group (A-C) and $n=28$ for the WT/VEH group, 25 for the WT/ActRIIB group, 37 for the H4OY/VEH group, and 29 for the H40Y/ActRIIB group (D). ${ }^{*} P<0.05,{ }^{* *} P<0.01$, and ${ }^{* * * P}<0.001$. ActRIIB, ActRIIB-mFc treated; VEH, vehicle; WT, wild type.

open field activity and treadmill performance did not detect significant differences between vehicle-treated WT and Actal H40Y mice at 2 to 16 weeks of age, despite the fact that a considerable number of Actal $\mathrm{H} 40 \mathrm{Y}$ mice were dying during this period (Figure 1). Compared with WT animals, antigravity hanging ability was mildly impaired in Actal $\mathrm{H} 40 \mathrm{Y}$ mice at 4 to $6.5 \mathrm{WOL}(\mathrm{WT} / \mathrm{vehicle}=52.75 \pm 3.96$ seconds versus $\mathrm{H} 40 \mathrm{Y} /$ vehicle $=27.85 \pm 4.54$ seconds at $4 \mathrm{WOL}, P<0.05$ ) but was similar to the antigravity hanging performance of WT mice after 6.5 WOL $(\mathrm{WT} / \mathrm{vehicle}=59.34 \pm 0.66$ seconds versus $\mathrm{H} 40 \mathrm{Y} /$ vehicle $=51.51 \pm 3.66$ seconds at $7 \mathrm{WOL}$ ). Similarly, treatment of WT and Actal H40Y mice with ActRIIB-mFc did not produce significant changes in antigravity hanging performance (data not shown), open field activity (Figure 1C), and treadmill performance (data not shown) at any time point. There was, however, a clear distinction between the vehicle-treated WT and Actal H40Y mice using forelimb grip strength testing beginning at $3 \mathrm{WOL}$ and persisting through the end of the study at $16 \mathrm{WOL}$ $(P<0.0001)$ (Figure 1B). Treatment of WT mice with ActRIIB-mFc produced a persistent increase in grip strength starting at $6 \mathrm{WOF}(P<0.01)$, which is similar in timing and extent to the effects of ActRIIB-mFc on WT mice in our prior studies. ${ }^{14,15}$ However, treatment of Actal H40Y mice with
ActRIIB-mFc did not significantly increase forelimb grip strength, although there was a nonsignificant trend toward slightly increased forelimb grip strength in ActRIIB-mFctreated Actal H40Y mice.

\section{Survival}

Similar to the first published characterization of Actal H40Y mice, we found that vehicle-treated male Actal $\mathrm{H} 40 \mathrm{Y}$ mice experienced significant mortality starting at approximately 6 WOL, with only $30 \%$ of vehicle-injected male Actal H40Y mice surviving to the end of the study at $16 \mathrm{WOL}$ (Figure 1D). Interestingly, this mortality was not accompanied by a decline in behavioral test performance in most of the mice, which suggested that the cause of death was not related directly to the inability to move, eat, or breathe. As previously described, ${ }^{18,31}$ this mortality was not observed in female Actal $\mathrm{H} 40 \mathrm{Y}$ mice, and our study focused on male Actal $\mathrm{H} 40 \mathrm{Y}$ mice because survival was a desirable functional end point in a treatment study. Treatment of male Actal H40Y mice with ActRIIB-mFc produced a significant improvement in survival, including higher overall survival (55\% survival to $16 \mathrm{WOL}, P<0.02$ ). In addition, although none of the vehicle-treated WT mice died during the 
Table 1 Contractile Properties of the Soleus and EDL in Treated and Untreated Mice

\begin{tabular}{|c|c|c|c|c|}
\hline Property & WT/VEH $(n=4)$ & WT/ActRIIB-mFc $(n=6)$ & H4OY/VEH $(n=2)$ & H40Y/ActRIIB-mFc $(n=5)$ \\
\hline \multicolumn{5}{|l|}{ Soleus muscle } \\
\hline Weight (mg) & $9.7 \pm 1.0$ & $12.9 \pm 0.7^{*}$ & $9.4 \pm 0.2$ & $9.5 \pm 1.3$ \\
\hline \multicolumn{5}{|l|}{ Twitch data } \\
\hline Force $(\mathrm{mN})$ & $31 \pm 4$ & $45 \pm 4^{*}$ & $34 \pm 2$ & $29 \pm 5$ \\
\hline Force $(\mathrm{mN} / \mathrm{CSA})$ & $35 \pm 2$ & $42 \pm 4$ & $38 \pm 1$ & $34 \pm 6$ \\
\hline $\mathrm{CT}$ (ms) & $88 \pm 8$ & $79 \pm 12$ & $118 \pm 10$ & $130 \pm 10^{\dagger}$ \\
\hline Force $(\mathrm{mN})$ & $162 \pm 15$ & $195 \pm 19$ & $139 \pm 35$ & $141 \pm 20$ \\
\hline Force $(\mathrm{mN} / \mathrm{CSA})$ & $187 \pm 11$ & $180 \pm 18$ & $155 \pm 35$ & $181 \pm 52$ \\
\hline$+\mathrm{dP} / \mathrm{dt}(\mathrm{mN} / \mathrm{s} / \mathrm{CSA})$ & $1311 \pm 53$ & $1930 \pm 150$ & $1279 \pm 122$ & $1184 \pm 327$ \\
\hline$-\mathrm{dP} / \mathrm{dt}(\mathrm{mN} / \mathrm{s} / \mathrm{CSA})$ & $-1124 \pm 190$ & $-946 \pm 192$ & $-537 \pm 208$ & $-804 \pm 277$ \\
\hline$V_{\max }(\mathrm{mL} / \mathrm{s})$ & $0.94 \pm 0.11$ & $1.50 \pm 0.35$ & & $0.70 \pm 0.01$ \\
\hline Force $(\mathrm{mN} / \mathrm{CSA})$ & $89 \pm 8$ & $83 \pm 11$ & $69 \pm 3$ & $60 \pm 8$ \\
\hline $\mathrm{CT}(\mathrm{ms})$ & $41 \pm 2$ & $37 \pm 1$ & $45 \pm 1$ & $37 \pm 1$ \\
\hline $1 / 2 \mathrm{RT}(\mathrm{ms})$ & $31 \pm 3$ & $26 \pm 4$ & $25 \pm 2$ & $36 \pm 4$ \\
\hline \multicolumn{5}{|l|}{ Tetanus data } \\
\hline Force $(\mathrm{mN})$ & $275 \pm 36$ & $339 \pm 36$ & $199 \pm 1$ & $170 \pm 28^{\dagger}$ \\
\hline Force $(\mathrm{mN} / \mathrm{CSA})$ & $300 \pm 44$ & $239 \pm 28$ & $232 \pm 46$ & $174 \pm 27$ \\
\hline$+\mathrm{dP} / \mathrm{dt}(\mathrm{mN} / \mathrm{s} / \mathrm{CSA})$ & $4896 \pm 521$ & $4999 \pm 576$ & $4607 \pm 33$ & $3852 \pm 568$ \\
\hline$-\mathrm{dP} / \mathrm{dt}(\mathrm{mN} / \mathrm{s} / \mathrm{CSA})$ & $-9977 \pm 1659$ & $-7065 \pm 1160$ & $-5943 \pm 1244$ & $-3674 \pm 840$ \\
\hline$V_{\max }(\mathrm{ML} / \mathrm{s})$ & $1.87 \pm 0.16$ & $2.32 \pm 0.25$ & & $1.40 \pm 0.20^{\dagger}$ \\
\hline
\end{tabular}

Values are expressed as means \pm SEM.

${ }^{*} P<0.05$ between WT/ActRIIB-mFc and WT/VEH.

${ }^{\dagger} P<0.05$ between Acta1 H40Y/ActRIIB-mFc and WT/ActRIIB-mFc.

${ }^{\ddagger} P<0.05$ between Acta1 H4OY/VEH and WT/VEH.

CSA, cross sectional area; $C T$, contraction time; $+d P / d t$, maximum rate of force development; $-\mathrm{dP} / \mathrm{dt}$, maximum rate of force decay; EDL, extensor digitorum longus; $1 / 2 \mathrm{RT}$, half relaxation time; VEH, vehicle; WT, wild type.

study, several ActRIIB-mFc-treated WT mice died at late stages of the trial because of apparent volume overload (indicated by large collections of nonbloody fluid in the thoracic cavity or both the thoracic and abdominal cavities). Histologic evaluation of tissue from the lungs of these animals did not reveal abnormalities. Specific gravity of the abdominal cavity fluid indicated that it was transudative rather than exudative (data not shown). This tended to occur in animals that were exceptionally large and heavy ( $>35 \mathrm{~g})$ and that were thus receiving large volumes of fluid with each dose of ActRIIB-mFc.

\section{In Vitro Contractile Properties}

Treatment of WT mice with ActRIIB-mFc caused a significant increase in muscle weight and twitch force in both the soleus and EDL compared with vehicle-treated WT mice (Table 1). Peak muscle power was also significantly increased with treatment of WT in both the soleus $\left(45.6 \pm 9.3\right.$ versus $\left.23.7 \pm 4.1 \mathrm{mN} \cdot \mathrm{ML}^{-1} \cdot \mathrm{s}^{-1}\right)$ and $\mathrm{EDL}$ $\left(137.1 \pm 32.9\right.$ versus $\left.67.8 \pm 23.0 \mathrm{mN} \cdot \mathrm{ML}^{-1} \cdot \mathrm{s}^{-1}\right)$. The EDL of vehicle-injected Actal H40Y mice had a depressed peak tetanic tension, and this effect was not reversed in the
ActRIIB-mFc-treated Actal $\mathrm{H} 40 \mathrm{Y}$ mice. The isometric $1 / 2$ RT was significantly prolonged in the soleus of vehicleinjected Actal H40Y mice but not the EDL $(P<0.05)$. In addition, the twitch contraction time revealed a trend toward prolongation $(P<0.1)$ in the soleus, but statistical evaluation was limited by the low numbers of vehicletreated Actal H40Y mice available for this portion of the study (because most mice in this group died before this 16 WOL evaluation point). ActRIIB-mFc treatment of the Actal $\mathrm{H} 40 \mathrm{Y}$ mice partially alleviated the lengthened soleus twitch duration by preventing prolongation of the $1 / 2 \mathrm{RT}$ (Table 1). These slightly differential abnormalities and treatment responses in the EDL and soleus muscles (which are enriched in glycolytic and oxidative fibers, respectively) suggest that the capacity for pharmacologically induced hypertrophy to improve weakness in NM may be partially dependent on fiber type.

\section{Pathologic Evaluation}

\section{Evidence of Muscle Growth}

Vehicle-injected Actal H40Y mice were easily distinguishable from vehicle-injected WT mice, primarily on the basis of 
muscle size. The weights of individual major muscles (quadriceps, triceps, gastrocnemius) were significantly smaller in vehicle-injected Actal H40Y mice compared with vehicleinjected WT mice $(P<0.0001)$ (Figure 2A). Muscle weight measurements at $16 \mathrm{WOL}$ found that ActRIIB-mFc treatment produced significant increases in the weights of the quadriceps, triceps, and gastrocnemius muscles compared with vehicle-treated mice of the same genotype $(P<0.001)$. There was no gross evidence of selective hypertrophy or atrophy of specific muscles.

Histologic evaluation of Actal H40Y mouse quadriceps muscle revealed numerous intracellular inclusions that were best visualized on Gomori trichrome stain, consistent with nemaline rods and with prior descriptions of muscle disease in this model (Figure 2B). ${ }^{18}$ Additional pathologic findings included excessive variation in fiber size and increased amounts of internally nucleated fibers. None of these pathologic findings were observed in WT quadriceps muscles. Mean \pm SD myofiber size of Actal H40Y mice $(37.94 \pm 0.58 \mu \mathrm{m})$ was only slightly smaller than that observed in WT mice (Table 2), although frequency histograms of fiber size revealed a difference in fiber size distributions due to disease $(P<0.05)$ (Figure $2 \mathrm{C})$. With respect to the effects of ActRIIB-mFc treatment, treated WT animals had increases in mean overall fiber size (irrespective of fiber type), which also corresponded to significant increases seen in both the oxidative and glycolytic myofiber subpopulations $(P<0.05)$ (Table 2$)$. The distribution of myofiber size in WT mice was shifted toward larger myofiber sizes as a result of ActRIIB-mFc treatment (Figure 2C and Table 2). Similarly, there was evidence of myofiber hypertrophy in Actal H40Y mice as a result of ActRIIB$\mathrm{mFc}$ treatment, consistent with the observed increase in muscle weights. Quantitative evaluation of mean myofiber size revealed a significant increase in Actal $\mathrm{H} 40 \mathrm{Y}$ oxidative fiber size with treatment, with nonsignificant trends toward increased mean fiber size in the glycolytic fiber population and in myofibers overall (Table 2). The myofiber size distributions of ActRIIB-mFc-treated Actal $\mathrm{H} 40 \mathrm{Y}$ mice were shifted toward larger myofiber sizes overall $(P<0.05)$ (Figure 2C). With respect to the presence of pathologic inclusions (nemaline rod aggregates), manual quantitation of fibers that contained aggregates of nemaline rods did not identify a treatment-associated decrease in these structures in the quadriceps muscle (Figure 2B and Table 2). The structure of these inclusions was investigated further by electron microscopy using glutaraldehyde-fixed tissue from the quadriceps muscle, which revealed the presence of nemaline rods and mitochondrial aggregates, sometimes in association with myofibrillar disarray (Supplemental Figure S1B). Myofibrillar inclusions were not observed in the absence of adjacent nemaline rod disease, although nemaline rods were sometimes present without evidence of myofibrillar disarray or mitochondrial aggregation.

The diaphragm and gastrocnemius muscles were also qualitatively evaluated histologically (Supplemental Figure S1A),
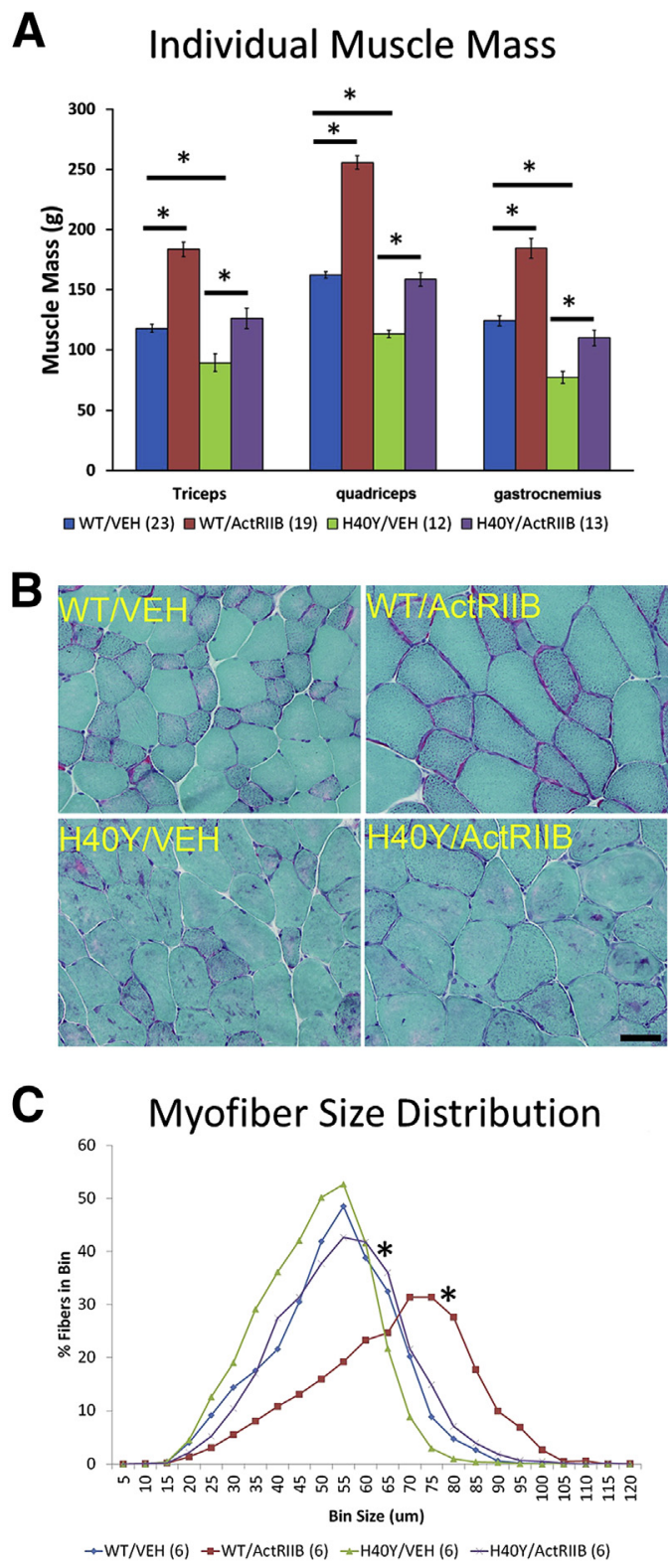

Figure 2 Skeletal muscle histopathologic findings in VEH- and ActRIIB$\mathrm{mFc}$-treated mice. A: Individual muscle weights from VEH- and ActRIIB$\mathrm{mFc}$-treated mice. Bars and asterisks denote significant $(P<0.05)$ differences between treatment groups with relevant comparisons. B: Representative areas of transversely sectioned quadriceps muscle after sectioning and staining with Gomori trichrome. Acta1 $\mathrm{H} 40 \mathrm{Y}$ mice have pathologic aggregates of purple/red material that corresponds to aggregates of nemaline rod material. C: Frequency histogram illustrating myofiber size distribution in the quadriceps muscles of VEH- and ActRIIB-treated mice. Asterisks reflect significant differences between treated and untreated animal groups, both in WT and Acta1 H4OY mice. ${ }^{*} P<0.05$. Scale bar $=$ $40 \mu \mathrm{m}$ (B). ActRIIB, ActRIIB-mFc treated; VEH, vehicle; WT, wild type.

but these muscles were not evaluated using quantitative methods. ActRIIB-mFc treatment produced marked hypertrophy of the diaphragm muscles of both WT and Actal H40Y mice, particularly in glycolytic myofibers. Treatment-induced myofiber hypertrophy was also apparent in the gastrocnemius muscles of WT mice, but treatment-induced hypertrophy was less apparent in Actal H40Y gastrocnemius muscles 
Table 2 Quantified Histologic Findings in Treated and Untreated Mice

\begin{tabular}{lcccc}
\hline Finding & WT/VEH & WT/ActRIIB-mFc & H4OY/VEH & H4OY/ActRIIB-mFc \\
\hline $\begin{array}{l}\text { Quadriceps muscle } \\
\quad \text { Mean myofiber size (MinFeret diameter, } \mu \mathrm{m})\end{array}$ & & & & \\
$\quad$ All fibers & $42.70 \pm 1.95$ & $55.49 \pm 2.04^{*}$ & $37.94 \pm 0.58$ & $44.46 \pm 1.93$ \\
$\quad$ Oxidative fibers & $30.08 \pm 1.02$ & $45.24 \pm 1.29^{*}$ & $33.93 \pm 0.80$ & $41.63 \pm 1.99^{\dagger}$ \\
$\quad$ Glycolytic fibers & $46.28 \pm 2.37$ & $62.90 \pm 2.60^{*}$ & $39.01 \pm 0.68$ & $45.76 \pm 2.27$ \\
$\quad$ Pathologic inclusions (\% of fibers) & $1.40 \pm 0.50$ & $0.90 \pm 0.74$ & $30.20 \pm 2.86$ & $35.50 \pm 1.97$ \\
Periurethral muscle & & & & \\
$\quad$ Myofiber size (MinFeret diameter, $\mu \mathrm{m})$ & $52.25 \pm 3.84$ & $53.65 \pm 3.90$ & $50.26 \pm 4.32$ & $53.67 \pm 4.77$ \\
$\quad$ Pathologic inclusions (\% of fibers) & $0.00 \pm 0.00$ & $0.00 \pm 0.00$ & $55.91 \pm 5.95$ & $46.2 \pm 8.66$ \\
$\quad$ Copulatory plugs (\% of animals) $(n / N)$ & $35(5 / 14)$ & $76(10 / 13)^{*}$ & $82(9 / 11)^{*}$ & $91(10 / 11)$ \\
$\quad$ Inflammation (\% of animals) $(n / N)$ & $0(0 / 14)$ & $0(0 / 13)$ & $91(10 / 11)^{\dagger}$ & $18(2 / 11)$ \\
\hline
\end{tabular}

Values are expressed as means \pm SEM unless otherwise indicated.

${ }^{*} P<0.05$ between WT/ActRIIB-mFc or Acta1 H40Y/VEH and WT/VEH.

${ }^{\dagger} P<0.05$ between Acta1 H4OY/ActRIIB-mFc and Acta1 H40Y/VEH.

VEH, vehicle; WT, wild type.

(compared with the WT gastrocnemius and the Actal H40Y quadriceps and diaphragm muscles). Similar to what was observed in the quadriceps muscle, there did not appear to be a treatment-related change in pathologic inclusions in the diaphragm or gastrocnemius muscles.

\section{Mortality of Acta1 H40Y Mice Is Associated with Bladder Outlet Obstruction}

The Actal H40Y mouse model has a curious pattern of mortality that is primarily restricted to a significant population of male mice at 5 to 13 WOL. This mortality is not observed in Actal H40Y females, implying that there may be critical sexrelated differences in mechanisms leading to mortality in this model. Indeed, further study of these mice revealed that myofilament function identified sex-related differences in the contractile performance of the tibialis anterior muscle, but there was no such dimorphism in the diaphragm, which is largely responsible for respiratory function. ${ }^{31}$ Necropsy findings performed in our study indicate that sex-related survival differences in Actal H40Y mice may primarily be caused by anatomical factors. Similar to prior studies, ${ }^{18}$ we have only observed significant mortality in the 5- to 13-week period in male mice in our Actal H40Y colony. Pathologic examination on necropsy revealed that mortality of Actal H40Y mice in our treatment study was typically associated with marked bladder distension (Figure 3, A and B) and accompanied by variable degrees of hemorrhage and necrosis in the genital and urinary tracts. In most cases, areas of induration, hemorrhage, and/or necrosis were clearly identified in the area of the prostatic urethra. This phenotype accounted for 34 of 36 Actal H40Y mice that died of disease during this study (23/24 in the Actal H40Y/vehicle group and 11/12 in the Actal H40Y/ ActRIIB-mFc group). Behaviorally, these animals had difficulty passing urine and had palpable distension of the bladder, but their ambulation and behavioral test results were not significantly affected until they were near-terminal. Dilatation of the bladder and ureters and hydronephrosis were observed in some animals, consistent with effects secondary to bladder outlet obstruction. This bladder outlet obstruction was not observed in the female Actal H40Y mice that were being used for breeding in our colony. Histologically, mice with bladder outlet obstruction typically had extensive inflammation of the urethra and surrounding tissues, particularly in the area of the prostate. Urinalysis results revealed increased numbers of red and white blood cells and increased urine protein in most cases (data not shown). Necrosis of this tissue and of tissues further upstream in the genital and urinary tracts was seen to variable degrees, but necrosis and inflammation of these regions were never seen in the absence of obstruction of the urethra. The nature of the obstruction and the assessment of muscle structure in the urethral striated muscles were not clearly evaluable because of the extensive inflammation and tissue damage seen in these animals. However, a systematic investigation of Actal H40Y mice that survived to the 16week study end point was performed, and the genitourinary tracts were thoroughly examined. Compared with vehicleinjected WT mice, ActRIIB-mFc-injected WT mice and all Actal H40Y mice had a greater percentage of copulatory plugs (a concretion formed by mice involved in reproductive behavior) (Figure 3, C and D) in the prostatic urethra. ${ }^{32,33}$ Copulatory plugs may be found as an incidental finding (due to agonal ejection of the plug) or as a legitimate cause of urinary tract obstruction, and the distinction often relies on the presence of inflammation as evidence of premortem obstruction. Inflammation of the genitourinary tract was quantified (in terms of its presence or absence in adequately sampled areas) as an indicator of significant premortem urinary tract obstruction, which revealed an absence of inflammation in WT mice, a very high number [11 (82\%) of 13 samples] of vehicle-injected Actal H40Y mice with inflammation and a significantly $(P<0.001)$ lower number of mice with inflammation in the ActRIIB-mFc-treated Actal H40Y group [2 (18\%) of 11 samples] (Figure 3E). This finding suggests treatment-associated changes to urethral striated muscle may allow improved copulatory plug ejection and prevent complications of urinary tract obstruction. Evaluation of urethral 

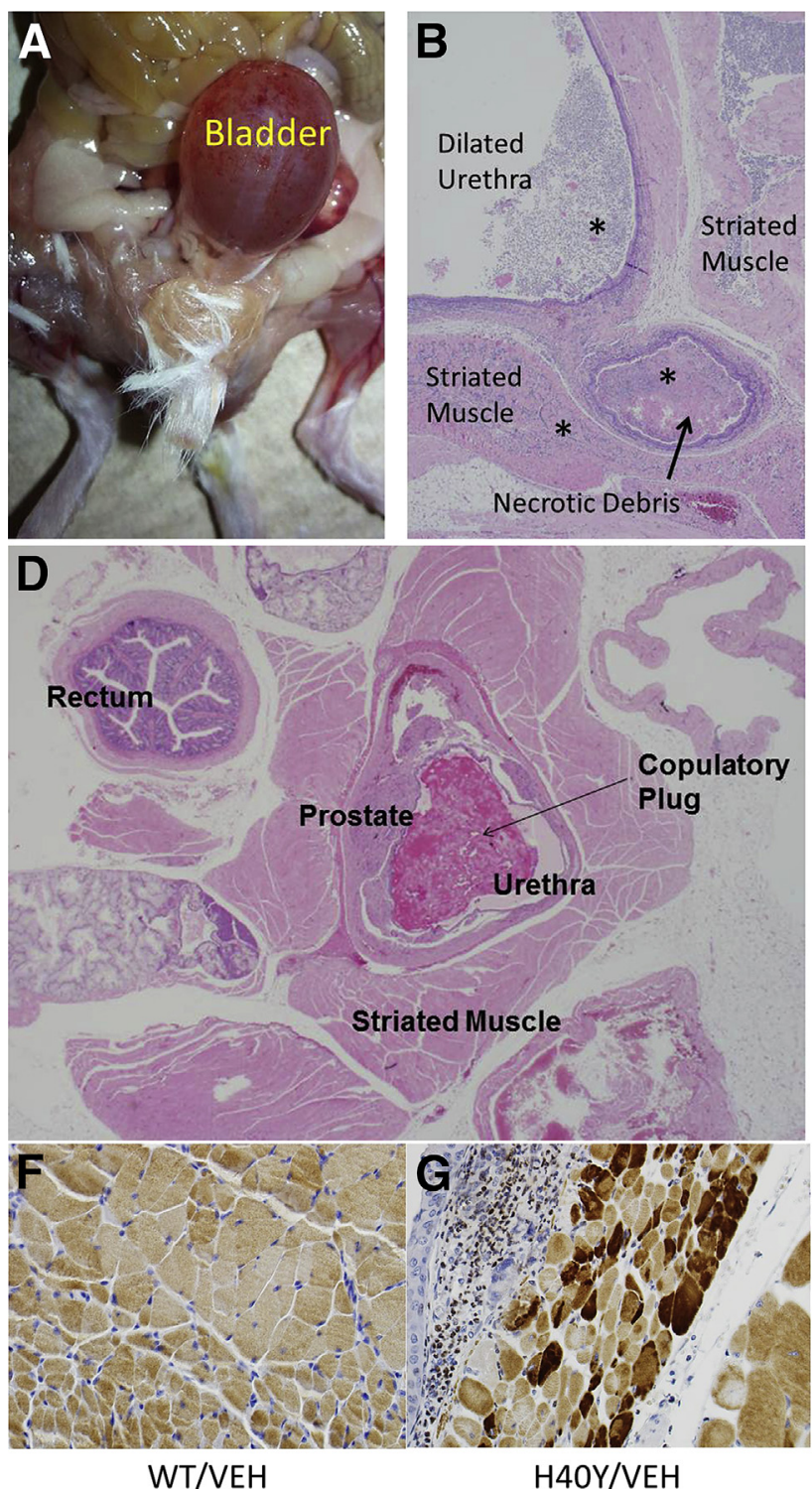

WT/VEH
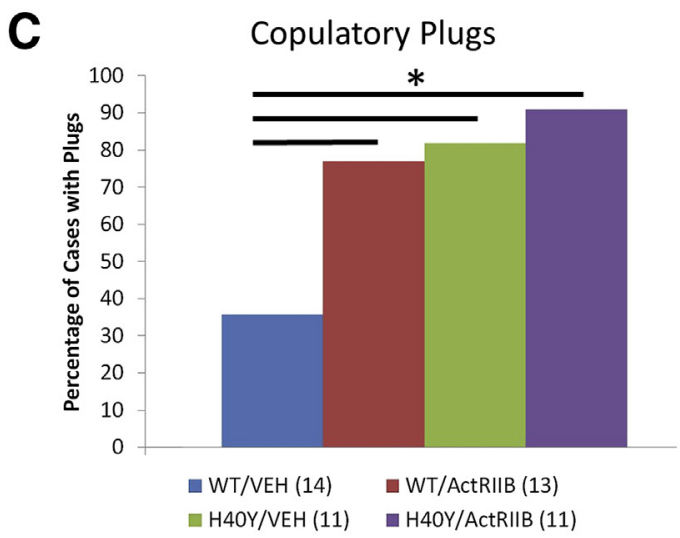

E

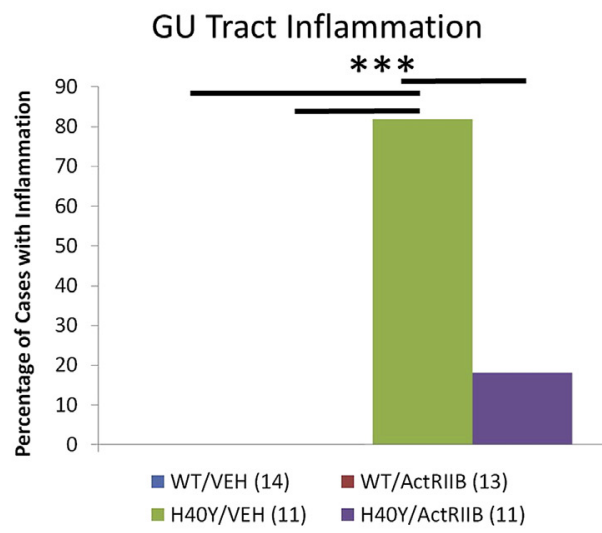

\section{H}

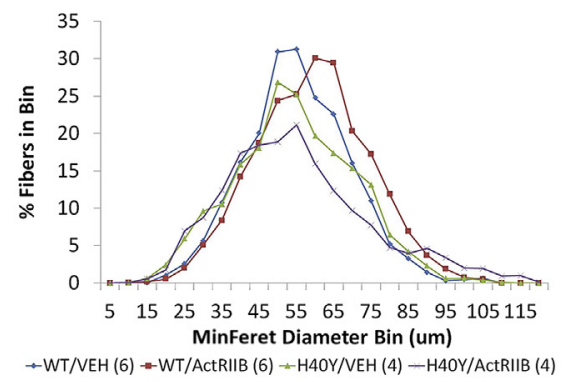

Figure 3 Genitourinary (GU) tract histopathologic findings in VEH- and ActRIIB-mFc-treated mice. A and B: Gross and histologic evidence of urethral obstruction leading to bladder distension, inflammation (asterisk) and necrosis in a subset of Acta1 $\mathrm{H} 40 \mathrm{Y}$ mice that died spontaneously during the trial. $\mathrm{C}$ and D: Assessment of copulatory plugs. C: Axial section of the GU tract of an ActRIIB-mFc-treated Acta1 H40Y mouse at 16 weeks of age. A copulatory plug is evident, as is a large amount of urethral striated muscle surrounding the prostate. There is no evidence of inflammation or tissue necrosis in this specimen. D: Quantification of mice exhibiting intraurethral copulatory plugs out of $(n)$ mice per group. E: Quantification of mice exhibiting GU tissue inflammation out of $(n)$ mice per group. $\mathbf{F}$ and $\mathbf{G}$ : Immunostaining of urethral striated muscles for skeletal muscle actin reveals pathologic aggregates of actin (corresponding to nemaline rod aggregates) in numerous fibers in Acta1 H40Y mice (G), whereas these aggregates are absent in WT littermates (F). H: Frequency histogram illustrating myofiber size distribution in urethral striated muscles of VEH- and ActRIIB-mFc-treated mice. ${ }^{*} P<0.05,{ }^{* *} P<0.001$. ActRIIB, ActRIIB-mFc treated; VEH, vehicle; WT, wild type.

striated muscle (likely involved in the ejection of copulatory plugs from the urethra) of male Actal $\mathrm{H} 40 \mathrm{Y}$ mice revealed marked NM, including actin-positive inclusions in many fibers (Figure 3, F and G). These inclusions likely corresponded to a combination of nemaline rods and myofibrillar material, similar to what was seen on electron microscopy of the quadriceps muscle (Supplemental Figure S1). Quantitative analysis of the urethral striated muscles revealed that the mean myofiber size was similar when comparing all four treatment groups (Table 2), although ActRIIB-mFc treatment produced slight trends toward increased mean fiber size in both WT and Actal H40Y mice (Figure 3H). Myofiber atrophy (as indicated by small fibers with angulated cellular contours) was observed in some Actal H40Y mice in association with inflammation, but these samples were not included in the quantitative analysis because of the likely effect of the inflammation. Actin-positive cytoplasmic inclusions were only seen in Actal H40Y (and not WT) mice, and there was a nonsignificant trend of decreased numbers of these inclusions in the urethral striated muscles of ActRIIB-mFc Actal H40Y 
A
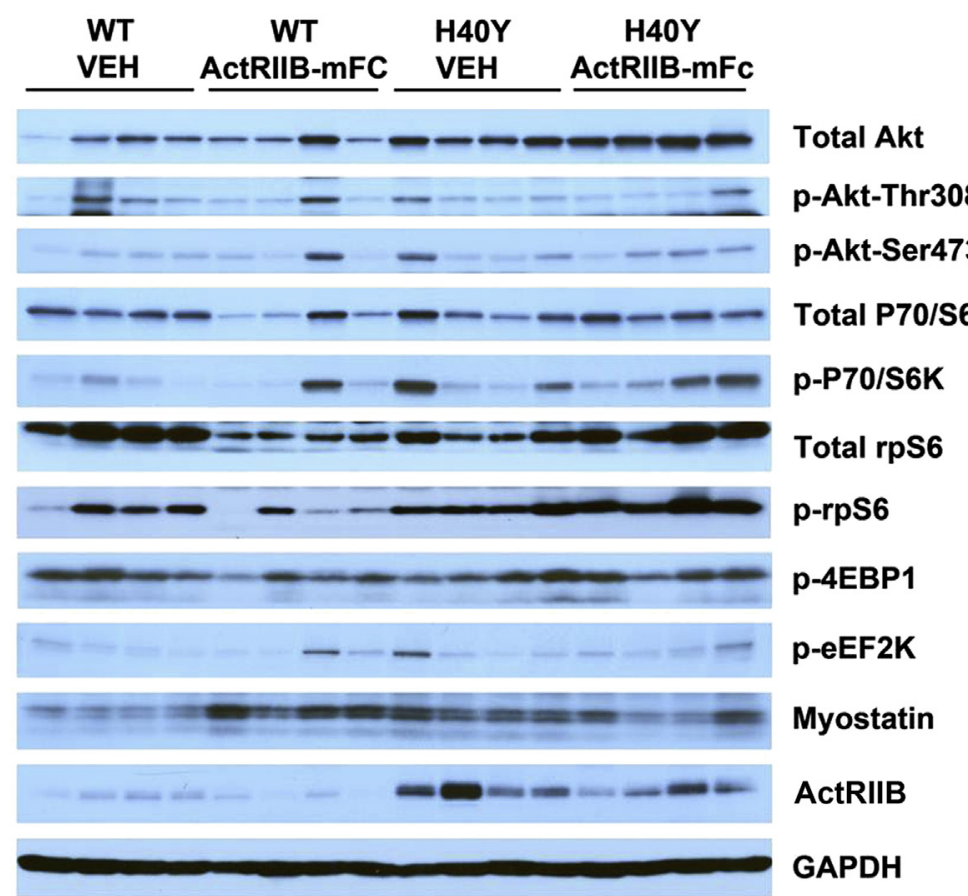

\section{Myostatin}

ActRIIB

GAPDH
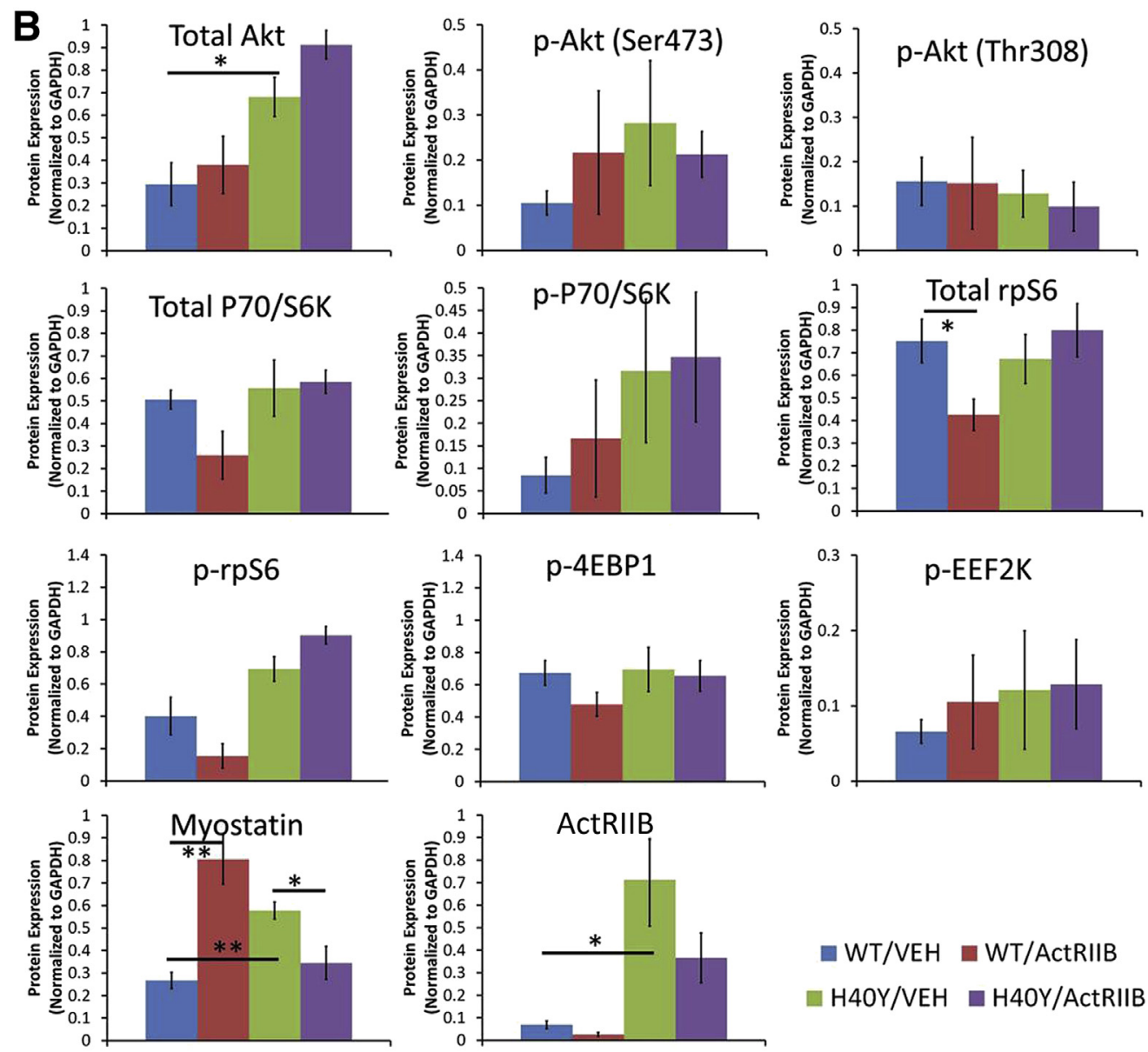

Figure 4 Expression of proteins related to myofiber growth in VEH- and ActRIIB-mFc-treated mice. A: Western blots reveal protein expression of growth-associated proteins in the quadriceps muscles of individual WT or Acta1 H40Y mice. B: Quantified protein expression (normalized to GAPDH expression) for each growth-associated protein shown in A. Protein extracted from the quadriceps muscle of four 16-week-old mice per treatment group were tested. ${ }^{*} P<0.05,{ }^{*} P<0.01$. ActRIIB, activin type IIB receptor; GAPDH, glyceraldehyde-3-phosphate dehydrogenase; VEH, vehicle; WT, wild type. 
mice $($ Actal H40Y/vehicle $=55.91 \% \pm 5.95 \%$, Actal H40Y $/$ ActRIIB $=46.2 \% \pm 8.66 \%$ ) (Table 2). Although other organs (including the heart, lungs, brain, liver, spleen, small intestine, and colon) were evaluated histologically at necropsy, no pathologic abnormalities were noted in these organs, including the lungs of treated WT mice that died during the treatment period.

\section{Hypertrophic Pathway Studies}

The activation of hypertrophic pathways in WT and Actal H40Y mice was investigated using Western blots. Phosphorylated and nonphosphorylated constituents of the Akt signaling pathway, including Akt, P70/S6k, rpS6, 4EBP1, and EEF2k, did not reveal significant differences with respect to genotype or treatment group (Figure 4). Levels of myostatin and the activin 2B receptor were both higher in vehicle-injected Actal H40Y mice compared with vehicle-injected WT mice $(P<0.05)$. Treatment of WT mice with ActRIIB-mFc produced an increase in myostatin levels $(P<0.05)$, which is consistent with the effects of this agent in WT mice in our prior studies. ${ }^{15}$ In Actal H40Y mice, treatment with ActRIIB-mFc produced a decrease in myostatin levels $(P<0.05)$. With respect to ActRIIB levels, vehicle-injected Actal H40Y mice had variable but considerably higher levels of this protein than vehicle-injected WT animals $(P<0.02)$. Treatment with ActRIIB-mFc in both WT and Actal H40Y mice produced nonsignificant trends toward lower ActRIIB levels.

\section{Discussion}

\section{Myostatin Inhibition as a Therapeutic Strategy in NM}

Because of the possible association between myofiber size and weakness, we hypothesized that the pharmacologic induction of hypertrophy through myostatin/ActRIIB inhibition would produce symptomatic benefits in murine NM models. Therapeutic benefits related to myofiber size could be applicable to patients with NM and other disorders in which myofiber hypotrophy is a key pathologic feature, such as congenital fiber-type disproportion. In our prior work using ActRIIB-mFc as a myostatin inhibition strategy in two murine models of XLMTM, we observed myofiber hypertrophy that was functionally limited by abnormalities of ECC that are seen in that disease. ${ }^{14,15,34-36}$ Because multiple studies of NM models and human NM tissue have identified intact ECC in $\mathrm{NM}^{16-23}$, we expected ActRIIB$\mathrm{mFc}$ treatment to be more effective in murine models of NM. In the present study, we treated the Actal H40Y murine model of NM with ActRIIB-mFc to determine the potential of this symptomatic strategy in at least a subset of patients with NM. ActRIIB-mFc-treated heterozygous male Actal H40Y mice experienced benefits to total-body mass, muscle mass, myofiber size, and survival, consistent with positive treatment-induced behavioral and pathologic effects. Surprisingly, we determined that mortality in male
Actal $\mathrm{H} 40 \mathrm{Y}$ mice is associated with complications of urethral obstruction. Further study found significant NM pathologic findings in the striated muscles surrounding the prostate and urethra, and we believe that this represents a phenotype that is related to muscle weakness.

The genetic heterogeneity of NM poses challenges for the development of treatments because any gene-specific treatment will likely only be suitable for a subpopulation of patients with NM. With respect to nonspecific therapies (such as hypertrophic therapies), it is currently difficult to predict treatment responsiveness across the NM patient population because the degree to which different genetic causes produce distinct disease states remains unclear. Transgenic knock-in or knockout mouse models exist for mutations found in the NEB,${ }^{20}$ ACTA1, ${ }^{18,19}$ TPM $3,{ }^{17}$ TNNT1,${ }^{37}$ CFL $2,{ }^{38}$ KBTBD13, and $\mathrm{KLHLAO}^{7}$ genes, and recent studies have explored treatment options in some of these models. For instance, the pathologic phenotype and clinical course of Actal H40Y mice were improved by crossing them with transgenic mice that produced myofiber hypertrophy through the overexpression of insulin-like growth factor-1 or FHL1 (but not c-ski), ${ }^{18}$ suggesting that induction of myofiber hypertrophy through at least some mechanisms would be beneficial in these mice. In addition, although the Tpm 3 M9R NM model required a period of disuse to promote weakness, exercise (and presumably the hypertrophy it caused) was found to be beneficial in the recovery of this weakness. ${ }^{39}$ These data suggest that hypertrophic agents (such as myostatin inhibitors) could provide substantial improvement of pathologic findings and symptoms in NM. These findings are also supported by reports of exercise as an effective strategy for minimizing disability in NM. ${ }^{40}$ In the current study, ActRIIB-mFc produced muscle hypertrophy but did not show the clear treatment-associated benefits to forelimb grip strength or ex vivo contractile function that were observed in treated WT littermates. The main evidence of therapeutic benefit was related to improvements in survival. Although this benefit is promising, further evaluation of myostatin inhibition in NM (in the context of other Actal models and models of other genetic causes of NM) is necessary to more definitively establish the potential of this therapeutic strategy.

\section{Pathologic Findings Associated with Mortality in this Study}

Prior work using the Actal H40Y model of NM described mortality of approximately half of hemizygote males at 1 to 3 months of age, ${ }^{18}$ which was presumably related to their skeletal muscle disease. A similar degree and timing of mortality were observed in the present study, but we additionally had the opportunity to look for unexpected causes of death in these mice because we evaluated them for potential systemic adverse effects. Surprisingly, most mice that died at 1 to 3 months of age had marked distension of the bladder with evident acute inflammation and necrosis in the genital and urinary tracts. This finding was consistent 
with the complications of obstruction in the distal urethra with secondary damage that involved more proximal regions of the genital and urinary tracts. Histologically, this was sometimes observed in association with a concretion of seminal secretions (the so-called copulatory plug) that is a normal finding in mice but is not a feature of human reproductive function. ${ }^{33}$ Although this copulatory plug is often observed within the urethra as an agonal finding and may produce bladder distension artifactually, the relevance of this finding in the current context is indicated by the presence of marked genitourinary inflammation in many Actal H40Y mice and the observation of apparent bladder distension and inability to pass urine in the terminal phase of disease in many Actal H40Y mice in our study. This phenomenon may explain the timing of mortality at 1 to 3 months (because this corresponds to a period when male mice reach sexual maturity and would begin producing these structures) and why female Actal H40Y mice do not experience mortality during this period. ${ }^{18}$ Pathologic evaluation of the genitourinary tract revealed that the urethral striated muscle had significant NM-associated pathologic findings in Actal $\mathrm{H} 40 \mathrm{Y}$ mice, including intracellular aggregates that are strongly positive for skeletal muscle actin. Urethral striated muscle is similar but developmentally distinct from skeletal muscle, ${ }^{41}$ and the involvement of this type of striated muscle (similar to the striated muscle of the esophagus and perianal region) has not been studied in NM. Although this striated muscle is structurally and functionally similar to skeletal muscle, it is developmentally derived from splanchnic mesoderm (instead of being derived from somites as limb skeletal muscles are). ${ }^{42,43}$ Our findings suggest that urethral striated muscle weakness seen in Actal H40Y mice may affect reproductive function in male mice to the extent that copulatory plugs cannot be passed from the membranous urethra. Actal H40Y mice that were treated with ActRIIB$\mathrm{mFc}$ had similar numbers of copulatory plugs, but the number of mice with genitourinary inflammation was markedly decreased. There were nonsignificant trends toward improved muscle condition in ActRIIB-mFc-treated urethral striated muscle (including trends toward larger fiber size and decreased numbers of fibers with pathologic inclusions). It is possible that treatment-associated changes in urethral striated muscle strength and power improved the ability to pass copulatory plugs through the urethra, thereby improving the survival of ActRIIB-mFc-treated Actal H40Y mice. The degree to which this phenotype is observed in other murine models of neuromuscular disease is unclear, but it may be useful to include studies of genitourinary anatomy in characterization or treatment studies of neuromuscular disease.

A recent study of Actal $\mathrm{H} 40 \mathrm{Y}$ mice has identified distinct causes of weakness in different muscle types (limb muscles versus diaphragm), ${ }^{44}$ and it is possible that a similar difference exists between limb muscles and urethral striated muscles. Weakness in limb muscles was primarily due to abnormalities in actin-myosin interactions that affected crossbridge cycling, whereas weakness in the diaphragm was more related to the presence of noncontractile areas in the myofibers. We found that ActRIIB-mFc induced hypertrophy in Actal $\mathrm{H} 40 \mathrm{Y}$ mice in the limb muscles but were unable to find improvements in limb muscle strength. In vitro studies of muscle contraction, however, found the treatment to maintain the velocity and power of the soleus and EDL muscles. However, pathologic findings indicative of urinary tract obstruction (inflammation of the genitourinary tract and gross evidence of obstruction) improved as a result of ActRIIB-mFc therapy. There were trends toward decreased numbers of urethral striated muscle fibers that contain pathologic aggregates of actin in ActRIIB-mFc-treated Actal H40Y mice (Table 2). Further study is required to determine the cause of weakness in Actal H40Y urethral striated muscles, but we posit that ActRIIB-mFc improves function of urethral striated muscle in a manner that is distinct from the major mechanisms responsible for weakness in limb muscles. Alternatively, it is possible that both limb skeletal muscles and urethral striated muscles have similar causes of weakness, but that the power required to eject copulatory plugs is considerably less than that required to produce measurable increases in isometric contraction strength.

With respect to the ActRIIB-mFc-treated WT mice who died late in the trial period, the presence of large amounts of transudative thoracic fluid suggests the accumulation of fluid as the result of injections. Because this study implemented a uniform concentration of drug across all groups and then based treatment volume on animal weight, the animals that were the heaviest were recurrently given the largest treatment volumes. The accumulation of fluid further contributed to animal weight and compounded the problem, resulting in marked fluid overload in some of our heaviest animals (all of which were in the WT/ActRIIB-mFc group). This thoracic fluid overload was not observed in the other treatment groups. To avoid this complication in future trials using ActRIIB$\mathrm{mFc}$, a higher concentration of the agent will be used to minimize the volume injected and improve clearance of fluid.

\section{Hypertrophic Signaling in Acta1 H40Y Mice}

Western blots were used in this study to determine the effect of the Actal $\mathrm{H} 40 \mathrm{Y}$ mutation on hypertrophic signaling, and the degree that ActRIIB-mFc therapy changed signaling in these pathways. We have used this strategy previously to detect disease- and muscle-specific signaling abnormalities that were associated with muscle-specific treatment effects with ActRIIB-mFc in murine models of X-linked myotubular myopathy. ${ }^{15}$ In this study, there was no evidence of muscleselective treatment efficacy (with respect to fiber type or muscle tested) in Actal H40Y mice. There were no significant differences in hypertrophic pathway signaling when comparing vehicle-injected WT and Actal H40Y mice, and treatment with ActRIIB-mFc did not significantly affect the levels of these proteins. There were, however, significant differences between WT and Actal H40Y mice with respect to the levels of myostatin and the ActRIIB, with 
vehicle-injected Actal H40Y mice having significantly higher levels of both proteins compared with vehicle-injected WT mice. This higher level of myostatin in affected mice may provide an explanation for the trend toward smaller myofibers in Actal H40Y mice (and the prior reports of myofiber smallness in these mice ${ }^{18}$ ). However, the degree to which higher myostatin or ActRIIB levels affect therapeutic effectiveness is unclear because, as a soluble receptor decoy, ActRIIB-mFc should prevent the binding of myostatin to the ActRIIB and induction of its signaling cascade. Overall, though, the key finding here is that there are no diseaseassociated abnormalities of hypertrophic signaling in Actal H40Y mice, and thus no expectation that strategies to induce hypertrophy would be impaired in this model.

Overall, these studies illustrate the first attempt at antimyostatin treatment in a mouse model of NM, which resulted in a variety of pathologic improvements and a moderate improvement in survival for male animals with urethral obstruction. Although muscle hypertrophy in response to treatment was apparent, there was little to no evidence of increased strength in limb muscles using a variety of assays. Treatment-related improvements in survival were associated with changes in the degree of genitourinary obstruction and inflammation in Actal $\mathrm{H} 40 \mathrm{Y}$ mice, which identified this phenomenon as a highly relevant phenotype in the assessment of this model. Because the circumstances of urinary obstruction are presumably due to weakness and pathologic findings in urethral striated muscles and this situation is unlikely to be unique to Actal H40Y mice, our study also identifies an important phenotype that should be considered across the spectrum of murine neuromuscular disease models.

\section{Acknowledgments}

Behavioral testing was performed at the Neuroscience Research Center's Behavioral Core Facility at the Medical College of Wisconsin. Histologic and imaging work was performed (in part) using the Histology and Imaging Core Facilities at the Children's Hospital of Wisconsin Research Institute. Electron microscopy was performed at the Electron Microscopy Core Facility at the Medical College of Wisconsin. Antibody clone BF-F3 was obtained from the Developmental Studies Hybridoma Bank, created by the National Institute of Child Health and Human Development of the NIH at the University of Iowa. We thank Dr. Greg Cox (Jackson Laboratories) for helpful discussions related to veterinary pathology.

\section{Supplemental Data}

Supplemental material for this article can be found at http://dx.doi.org/10.1016/j.ajpath.2016.02.008.

\section{References}

1. North KN, Laing NG, Wallgren-Pettersson C: Nemaline myopathy: current concepts. The ENMC International Consortium and Nemaline Myopathy. J Med Genet 1997, 34:705-713
2. Wallgren-Pettersson C, Sewry CA, Nowak KJ, Laing NG: Nemaline myopathies. Semin Pediatr Neurol 2011, 18:230-238

3. Gupta VA, Ravenscroft G, Shaheen R, Todd EJ, Swanson LC, Shiina M, Ogata K, Hsu C, Clarke NF, Darras BT, Farrar MA, Hashem A, Manton ND, Muntoni F, North KN, Sandaradura SA, Nishino I, Hayashi YK, Sewry CA, Thompson EM, Yau KS, Brownstein CA, Yu TW, Allcock RJ, Davis MR, WallgrenPettersson C, Matsumoto N, Alkuraya FS, Laing NG, Beggs AH: Identification of KLHL41 mutations implicates BTB-Kelch-mediated ubiquitination as an alternate pathway to myofibrillar disruption in nemaline myopathy. Am J Hum Genet 2013, 93:1108-1117

4. Ravenscroft G, Miyatake S, Lehtokari VL, Todd EJ, Vornanen P, Yau KS, et al: Mutations in KLHL40 are a frequent cause of severe autosomal recessive nemaline myopathy. Am J Hum Genet 2013, 93:6-18

5. Yuen M, Sandaradura SA, Dowling JJ, Kostyukova AS, Moroz N, Quinlan KG, et al: Leiomodin-3 dysfunction results in thin filament disorganization and nemaline myopathy. J Clin Invest 2014, 124: 4693-4708

6. Sanoudou D, Beggs AH: Clinical and genetic heterogeneity in nemaline myopathy - a disease of skeletal muscle thin filaments. Trends Mol Med 2001, 7:362-368

7. Garg A, O'Rourke J, Long C, Doering J, Ravenscroft G, Bezprozvannaya S, Nelson BR, Beetz N, Li L, Chen S, Laing NG, Grange RW, Bassel-Duby R, Olson EN: KLHL40 deficiency destabilizes thin filament proteins and promotes nemaline myopathy. J Clin Invest 2014, 124:3529-3539

8. Dubowitz V, Sewry C, Oldfors A: Congenital myopathies and related disorders. Edited by Dubowitz V, Sewry C, Oldfors A. Muscle Biopsy: A Practical Approach. Philadelphia, PA: Saunders Elsevier, 2013, pp $358-405$

9. Imoto C, Nonaka I: The significance of type 1 fiber atrophy (hypotrophy) in childhood neuromuscular disorders. Brain Dev 2001, 23:298-302

10. Clarke NF, Kolski H, Dye DE, Lim E, Smith RL, Patel R, Fahey MC, Bellance R, Romero NB, Johnson ES, Labarre-Vila A, Monnier N, Laing NG, North KN: Mutations in TPM3 are a common cause of congenital fiber type disproportion. Ann Neurol 2008, 63:329-337

11. Lawlor MW, Dechene ET, Roumm E, Geggel AS, Moghadaszadeh B, Beggs AH: Mutations of tropomyosin 3 (TPM3) are common and associated with type 1 myofiber hypotrophy in congenital fiber type disproportion. Hum Mutat 2010, 31:176-183

12. McCroskery S, Thomas M, Maxwell L, Sharma M, Kambadur R: Myostatin negatively regulates satellite cell activation and selfrenewal. J Cell Biol 2003, 162:1135-1147

13. Joulia-Ekaza D, Cabello G: Myostatin regulation of muscle development: molecular basis, natural mutations, physiopathological aspects. Exp Cell Res 2006, 312:2401-2414

14. Lawlor MW, Read BP, Edelstein R, Yang N, Pierson CR, Stein MJ, Wermer-Colan A, Buj-Bello A, Lachey JL, Seehra JS, Beggs AH: Inhibition of activin receptor type IIb increases strength and lifespan in myotubularin-deficient mice. Am J Pathol 2011, 178:784-793

15. Lawlor MW, Viola MG, Meng H, Edelstein RV, Liu F, Yan K, Luna EJ, Lerch-Gaggl A, Hoffmann RG, Pierson CR, Buj-Bello A, Lachey JL, Pearsall S, Yang L, Hillard CJ, Beggs AH: Differential muscle hypertrophy is associated with satellite cell numbers and Akt pathway activation following activin type IIB receptor inhibition in Mtm1 p.R69C mice. Am J Pathol 2014, 184:1831-1842

16. Chandra M, Mamidi R, Ford S, Hidalgo C, Witt C, Ottenheijm C, Labeit S, Granzier H: Nebulin alters cross-bridge cycling kinetics and increases thin filament activation: a novel mechanism for increasing tension and reducing tension cost. J Biol Chem 2009, 284: 30889-30896

17. de Haan A, van der Vliet MR, Gommans IM, Hardeman EC, van Engelen BG: Skeletal muscle of mice with a mutation in slow alphatropomyosin is weaker at lower lengths. Neuromuscul Disord 2002, 12:952-957

18. Nguyen MA, Joya JE, Kee AJ, Domazetovska A, Yang N, Hook JW, Lemckert FA, Kettle E, Valova VA, Robinson PJ, North KN, 
Gunning PW, Mitchell CA, Hardeman EC: Hypertrophy and dietary tyrosine ameliorate the phenotypes of a mouse model of severe nemaline myopathy. Brain 2011, 134:3516-3529

19. Ravenscroft G, Jackaman C, Bringans S, Papadimitriou JM, Griffiths LM, McNamara E, Bakker AJ, Davies KE, Laing NG, Nowak KJ: Mouse models of dominant ACTA1 disease recapitulate human disease and provide insight into therapies. Brain 2011, 134:1101-1115

20. Witt CC, Burkart C, Labeit D, McNabb M, Wu Y, Granzier H, Labeit S: Nebulin regulates thin filament length, contractility, and Z-disk structure in vivo. EMBO J 2006, 25:3843-3855

21. Ottenheijm CA, Hooijman P, DeChene ET, Stienen GJ, Beggs AH, Granzier H: Altered myofilament function depresses force generation in patients with nebulin-based nemaline myopathy (NEM2). J Struct Biol 2010, 170:334-343

22. Ottenheijm CA, Lawlor MW, Stienen GJ, Granzier H, Beggs AH: Changes in cross-bridge cycling underlie muscle weakness in patients with tropomyosin 3-based myopathy. Hum Mol Genet 2011, 20:2015-2025

23. Ottenheijm CA, Witt CC, Stienen GJ, Labeit S, Beggs AH, Granzier H: Thin filament length dysregulation contributes to muscle weakness in nemaline myopathy patients with nebulin deficiency. Hum Mol Genet 2009, 18:2359-2369

24. Troup JP, Metzger JM, Fitts RH: Effect of high-intensity exercise training on functional capacity of limb skeletal muscle. J Appl Physiol (1985) 1986, 60:1743-1751

25. Hurst JE, Fitts RH: Hindlimb unloading-induced muscle atrophy and loss of function: protective effect of isometric exercise. J Appl Physiol (1985) 2003, 95:1405-1417

26. Brooke MH, Engel WK: The histographic analysis of human muscle biopsies with regard to fiber types, 4: children's biopsies. Neurology 1969, 19:591-605

27. Kheir JN, Scharp LA, Borden MA, Swanson EJ, Loxley A, Reese JH, Black KJ, Velazquez LA, Thomson LM, Walsh BK, Mullen KE, Graham DA, Lawlor MW, Brugnara C, Bell DC, McGowan FX Jr: Oxygen gas-filled microparticles provide intravenous oxygen delivery. Sci Transl Med 2012, 4:140ra88

28. Moghadaszadeh B, Rider BE, Lawlor MW, Childers MK, Grange RW, Gupta K, Boukedes SS, Owen CA, Beggs AH: Selenoprotein N deficiency in mice is associated with abnormal lung development. FASEB J 2013, 27:1585-1599

29. Wattanasirichaigoon D, Swoboda KJ, Takada F, Tong HQ, Lip V, Iannaccone ST, Wallgren-Pettersson C, Laing NG, Beggs AH: Mutations of the slow muscle alpha-tropomyosin gene, TPM3, are a rare cause of nemaline myopathy. Neurology 2002, 59:613-617

30. Rasband WS: ImageJ. Bethesda, Maryland, National Institutes of Health, 1997-2012

31. Lindqvist J, Hardeman EC, Ochala J: Sexually dimorphic myofilament function in a mouse model of nemaline myopathy. Arch Biochem Biophys 2014, 564:37-42

32. Gaillard ET: Ureter, Uninary Bladder, and Urethra. Edited by Maronpot RR. Pathology of the Mouse. ed 1. St. Louis, MO: Cache River Press, 1999, pp 235-258
33. Knoblaugh S, True L: Male Reproductive System. Edited by Treuting PM, Dintzis SM. Comparative Anatomy and Histology: A Mouse and Human Atlas. Philadelphia, PA: Elsevier, 2012, pp 285-308

34. Al-Qusairi L, Weiss N, Toussaint A, Berbey C, Messaddeq N, Kretz C, Sanoudou D, Beggs AH, Allard B, Mandel JL, Laporte J, Jacquemond V, Buj-Bello A: T-tubule disorganization and defective excitation-contraction coupling in muscle fibers lacking myotubularin lipid phosphatase. Proc Natl Acad Sci U S A 2009, 106: $18763-18768$

35. Dowling JJ, Vreede AP, Low SE, Gibbs EM, Kuwada JY, Bonnemann CG, Feldman EL: Loss of myotubularin function results in T-tubule disorganization in zebrafish and human myotubular myopathy. PLoS Genet 2009, 5:e1000372

36. Lawlor MW, Armstrong D, Viola MG, Widrick JJ, Meng H, Grange RW, Childers MK, Hsu CP, O'Callaghan M, Pierson CR, BujBello A, Beggs AH: Enzyme replacement therapy rescues weakness and improves muscle pathology in mice with X-linked myotubular myopathy. Hum Mol Genet 2013, 22:1525-1538

37. Wei B, Lu Y, Jin JP: Deficiency of slow skeletal muscle troponin $\mathrm{T}$ causes atrophy of type I slow fibers and decreases tolerance to fatigue. J Physiol 2014, 592:1367-1380

38. Agrawal PB, Joshi M, Savic T, Chen Z, Beggs AH: Normal myofibrillar development followed by progressive sarcomeric disruption with actin accumulations in a mouse $\mathrm{Cfl} 2$ knockout demonstrates requirement of cofilin-2 for muscle maintenance. Hum Mol Genet 2012, 21:2341-2356

39. Joya JE, Kee AJ, Nair-Shalliker V, Ghoddusi M, Nguyen MA, Luther P, Hardeman EC: Muscle weakness in a mouse model of nemaline myopathy can be reversed with exercise and reveals a novel myofiber repair mechanism. Hum Mol Genet 2004, 13: $2633-2645$

40. Ilkovski B, Cooper ST, Nowak K, Ryan MM, Yang N, Schnell C, Durling HJ, Roddick LG, Wilkinson I, Kornberg AJ, Collins KJ, Wallace G, Gunning P, Hardeman EC, Laing NG, North KN: Nemaline myopathy caused by mutations in the muscle alpha-skeletal-actin gene. Am J Hum Genet 2001, 68:1333-1343

41. Masumoto H, Takenaka A, Rodriguez-Vazquez JF, Murakami G, Matsubara A: Reappraisal of intergender differences in the urethral striated sphincter explains why a completely circular arrangement is difficult in females: a histological study using human fetuses. Anat Cell Biol 2012, 45:79-85

42. Borirakchanyavat S, Baskin LS, Kogan BA, Cunha GR: Smooth and striated muscle development in the intrinsic urethral sphincter. J Urol 1997, 158:1119-1122

43. Lin G, Huang YC, Wang G, Lue TF, Lin CS: Prominent expression of phosphodiesterase 5 in striated muscle of the rat urethra and levator ani. J Urol 2010, 184:769-774

44. Lindqvist J, Cheng AJ, Renaud G, Hardeman EC, Ochala J: Distinct underlying mechanisms of limb and respiratory muscle fiber weaknesses in nemaline myopathy. J Neuropathol Exp Neurol 2013, 72: $472-481$ 